\title{
Prediction of Natural Gas Z-Factor by Using ANN Method
}

\author{
. Ebrahimi-Moghadam*, B. Mohseni-Gharyehsafa, A. Jabari moghadam, M. Farzaneh-Gord, Y. \\ Bijarzehi and V. Okati
}

\begin{abstract}
Calculation of the natural gas thermodynamic properties is one of the most important topics in natural gas industry. To calculate the natural gas thermodynamic properties, the compressibility factor must first be calculated. Accordingly, the aim of current investigation is to calculate the natural gas compressibility factor in different conditions with high accuracy. AGA8 EOS is one of the well-known and accurate EOSs in natural gas industry which historically is used for determining natural gas properties. Although, AGA8 equation of state could predict compressibility factor precisely but has a few limitations. In current investigation, an Artificial Neural Network (ANN) is used to overcome this limitation and also speed up calculations. The use of the ANN systems for predicting natural gas properties is a novel method in this field which limited researches have been done around it. The inputs of the ANN system are temperature, pressure and mole fraction of the natural gas components and the output is compressibility factor. For training the ANN system, more than 20000 datasets are collected from AGA8 EOS. This data number is higher than all previous studies in this field and guarantees the high accuracy of the calculations. The results show that the errors of the ANN predictions are less $1 \%$ at temperature and pressures that describes in AGA8 validation range which proves the accuracy of ANN model.
\end{abstract}

Index Terms - Natural gas, Compressibility factor, Artificial neural network (ANN).

\section{INTRODUCTION}

Various components are involved in natural gas composition and the natural gas is used in many aims around the world [1]. To understand natural gas, its thermodynamics properties must be recognized and one of the main thermodynamics properties is compressibility factor which it affects the rest of the property [2].

The methods for determining the thermodynamic property of natural gas are mainly divided into three broad categories: measuring and laboratory instruments, equations of state (EOS) and intelligent methods.

Many measuring devices have been developed to measure mass flow rate and volume flow rate of natural gas. Zhou et al. [3] used an apparatus to measure pressure and temperature of gas mixtures according on the isochoric method. Valdes and

A. Ebrahimi-Moghadam, B. Mohseni-Gharyehsafa, A. Jabari moghadam, M. Farzaneh-Gord, V. Okati, Faculty of Mechanical Engineering, Shahrood University of technology, Shahrood, Iran

Y. Bijarzehi, Saba Operation and Maintenance Company, Tehran, Iran.

V. Okati, Faculty of Marine Engineering, Chabahar Maritime University, Chabahar, Iran.
Cadet [4] used ultrasonic time-of-flight method for calculating molecular weight of a binary gas mixture. The main disadvantage of the mentioned researches is the requirement for frequent calibration of the device [5].

Applying the EOSs is another procedure for calculating the gas mixture properties. Among the several EOSs for natural gas, AGA8 [6] equation is the well-known equation. Londono et al. [7] proposed simple correlation to calculate hydrocarbon gases density. Gysling [8] reported an aeroelastic model of Coriolis mass and density meter. In another work, a correlation for calculating gas density was developed by Dranchuk and Abou-Kassem [9] by using 1500 data points for both pure gases and mixtures.

Intelligent methods are used for estimating the natural gas properties in current days. One of these methods, the artificial neural network (ANN) [10], has attracted a lot of attention due to the high accuracy of the calculations. Increasing accuracy of estimating the compressibility factor calculations is one of the topics that recently have been done about it. The first researches in this field was done by Moghadassi et al. [11] and Kamyab et al.[12]. Kamyab et al. [12] applied an ANN and used Katz diagram in order to supply the input data for ANN.

As it mentioned, the use of intelligent methods for predicting natural gas properties is a broad topic which limited researches have been done about it. This investigation is paid to train an accurate ANN system for estimating compressibility factor of the natural gas. The training data for the ANN are collected from AGA8 EOS results. The most important innovation of this present research is that over 20000 are prepared for training ANN and when a massive data set entered for the training, ANN can predict more better the relations between inputs and output and also as it said above the training data collected from a proved correlation, AGA8 EOS, which is more accurate than other empirical equations.

\section{PRoblem StatemenT}

In general, the EOS of a real gas is defined as Eq. 1. In Eq. 1, the compressibility factor can be determined by using AGA8 EOS as Eq. 2.

$$
\begin{aligned}
& p V=Z \rho_{m} R T \\
& Z=1+B \rho_{m}-\rho_{r} \sum_{n=13}^{18} C_{n}^{*}+\sum_{n=13}^{58} C_{n}^{*} D_{n}^{*}
\end{aligned}
$$


In which, $B, \rho_{r}, C_{n}^{*}$ and $D_{n}^{*}(n=1, \ldots, 58)$ are the second virial coefficient, reduced density and AGA8 EOS coefficients, respectively. The AGA8 EOS coefficients are completely defined in [6].

Inputs data for this investigation are volume fraction of the components $X$, temperature $T$ and pressure $p$ and output is compressibility factor $(Z)$. The transfer function which used is sigmoid transfer function that is one of most common transformation function in neural networks Eq. 3 and three statistical are used for determining the accuracy of the ANN (Eq. 4 to Eq. 6). Fig 1 presents a summary of the trained network, including the number of input data, the number of layers, which includes an input layer that contains problem inputs and two hidden layer that have the task of finding the relationship between inputs and outputs and output layer which provides compressibility factor.

$g(Z)=\frac{1}{1+\exp (-Z)}$

TABLE I: STATISTICAL ERROR PARAMTERES

\begin{tabular}{|c|c|}
\hline $\begin{array}{l}\text { Root mean square } \\
\text { error(RMSE) }\end{array}$ & $R M S E=\sqrt{\frac{1}{n}} \sum_{i=1}^{n}\left(Z_{t, i}-Z_{A N N, i}\right)^{2}$ \\
\hline $\begin{array}{l}\text { Coefficient of } \\
\text { determination }\left(\mathrm{R}^{2}\right)\end{array}$ & $R^{2}=1-\frac{\sum_{k=1}^{n}\left(Z_{A N, k}-Z_{t, k}\right)}{\sum_{k=1}^{n}\left(Z_{A N N_{,} k}-Z_{t, m}\right)}, Z_{t, m}=\frac{\sum_{k=1}^{n} Z_{A N N, k}}{n}$ \\
\hline $\begin{array}{l}\text { Relative difference } \\
\text { error (ERROR\%) }\end{array}$ & $\operatorname{ERROR}(\%)=\left(\frac{Z_{\text {experimental }}-Z_{\text {ANN }}}{Z_{\text {experimental }}}\right) \times 100$ \\
\hline
\end{tabular}

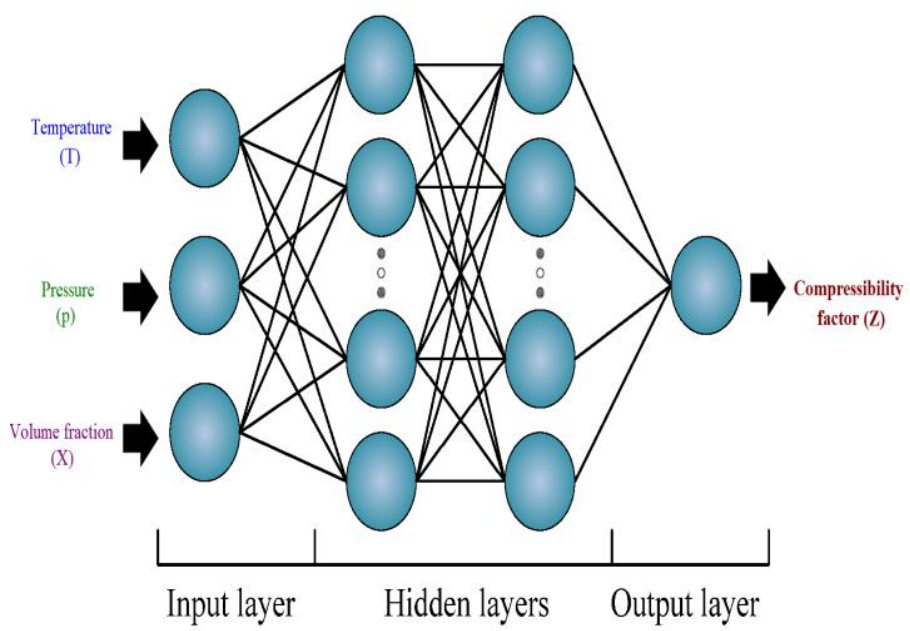

Fig 1: Summary of the neural network architecture.

\section{RESULT AND DISCUSSION}

As it mentioned before, over 20000 datasets has been fed into ANN which $75 \%$ of these data used as input, $15 \%$ used as validation check and the rest of them used as test data. Data prepare from AGA8 EOS for randomly range of temperature $140.15<\mathrm{T}[\mathrm{K}] \quad<473.15$ and pressure $0<\mathrm{P} \quad[\mathrm{MPa}]<140$. According to Table I. the root mean square error for the train data, validation check data and test data are as follows:0.0046355, 0.0043124 and 0.0051255 which these data are very close to zero, that indicates the high accuracy of the network training, and also coefficient of determination which the closer this coefficient to one, the better is training of the data ,for train, validation and test data are respectively 0.9999 , 0.9998 and 0.9998.Fig 2. and Fig 4. shows predicted values for compressibility factor obtain from ANN respectively for pure methane and McElroy et al. [13]. Fig. 3 and Fig. 5 shows scattered error according to Eq. 6 for these compositions, And also Fig 6. for Turkman gas [14] show relative error between AGA8 EOS and ANN results and it can be understood from all scattered figures that errors for this trained ANN are less than $0.5 \%$ that it guarantees the good training ANN.

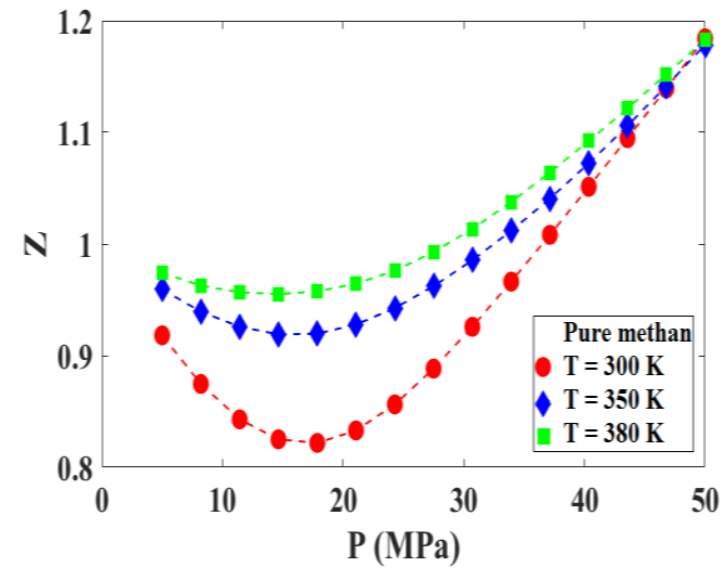

Fig 2: Compressibility factor prediction for pure methane by ANN

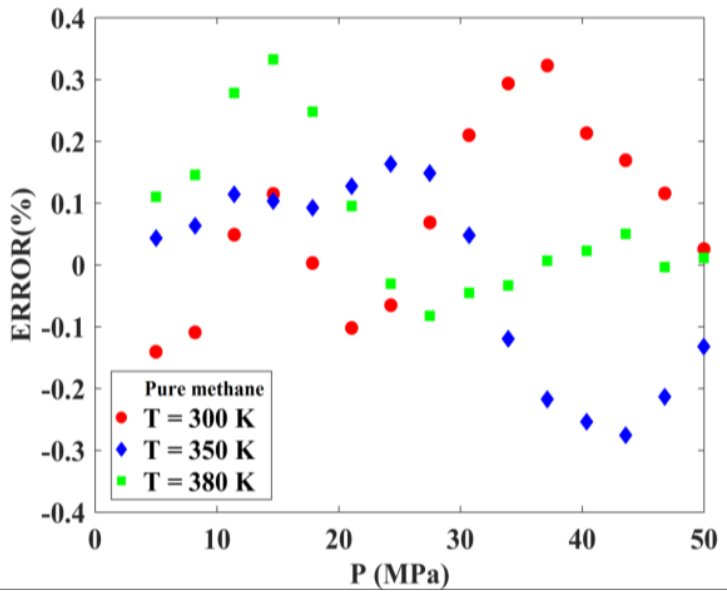

Fig 3: Relative difference for compressibility factor between ANN and experimental results [Pure methane]

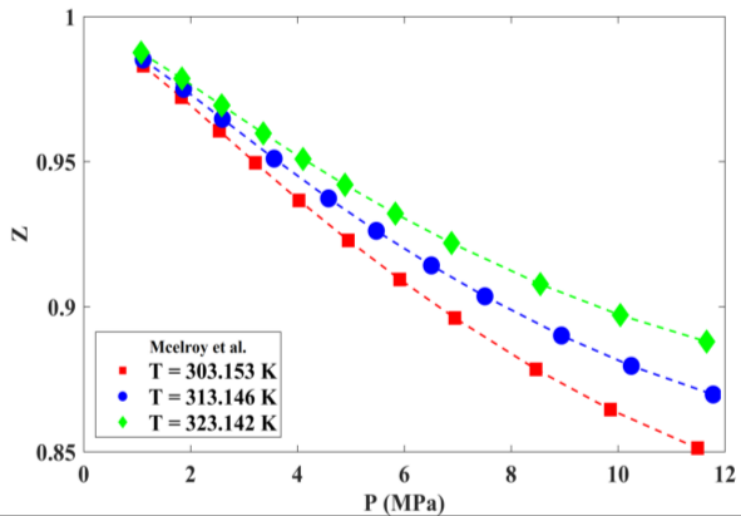

Fig 4: Compressibility factor prediction for McElroy et al. [13] by ANN 


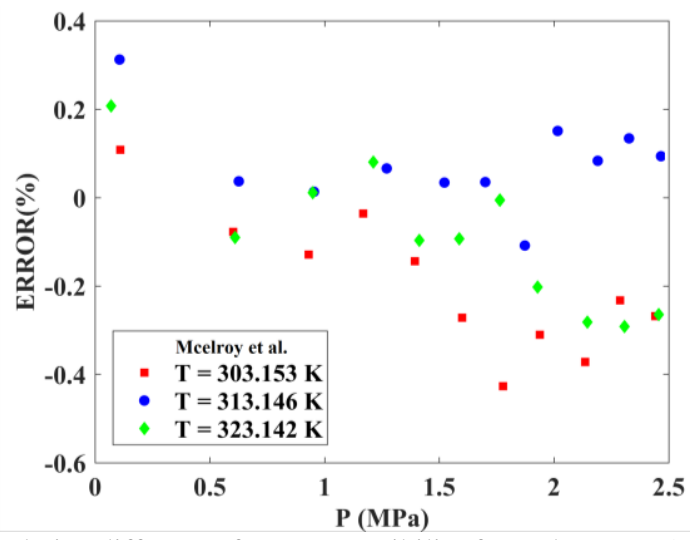

Fig 5: Relative difference for compressibility factor between ANN and experimental results [McElroy et al.[13]]

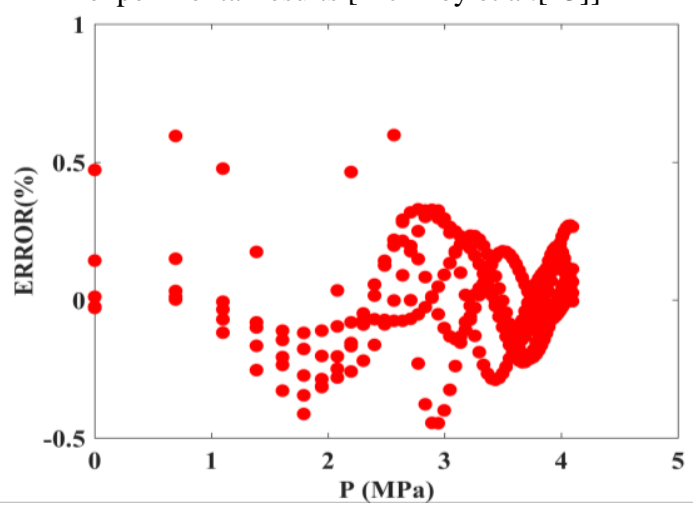

Fig 6: Relative difference for compressibility factor between ANN and AGA8 results [Turkman gas [14]]

\section{CONCLUSION}

This paper have been paid to obtain high accurate estimation of compressibility factor for natural gas which this thermodynamics property appears in calculations of other thermodynamics properties so the accuracy of estimation plays a vital role and to get a best calculation, an ANN had been trained from a well Known EOS, AGA8, and the results shows the best performance of this ANN which the relative error between estimated compressibility factor from ANN and experimental results.

\section{ACKNOWLEDGMENT}

This study was funded by Shahrood University of Technology .

\section{REFERENCES}

[1] A. Ebrahimi-Moghadam, M. Farzaneh-Gord, and M. Deymi-Dashtebayaz, "Correlations for estimating natural gas leakage from above-ground and buried urban distribution pipelines," J. Nat. Gas Sci. Eng., vol. 34, no. Supplement C, pp. 185-196, 2016.

[2] M. Farzaneh-Gord, A. Niazmand, M. Deymi-Dashtebayaz, and H. R. Rahbari, "Effects of natural gas compositions on CNG (compressed natural gas) reciprocating compressors performance," Energy, vol. 90, no. Part 1, pp. 1152-1162, 2015.

[3] J. Zhou, P. Patil, S. Ejaz, M. Atilhan, J. C. Holste, and K. R. Hall, " $(\mathrm{p}, \mathrm{Vm}, \mathrm{T})$ and phase equilibrium measurements for a natural gas-like mixture using an automated isochoric apparatus," J. Chem. Thermodyn., vol. 38, no. 11, pp. 1489-1494, 2006. https://doi.org/10.1016/j.jct.2005.12.011
[4] J. L. Valdes and G. Cadet, "Ultrasonic time-of-flight method for on-line quantitation of in situ generated arsine," Anal. Chem., vol. 63, no. 4, pp. 366-369, Feb. 1991. https://doi.org/10.1021/ac00004a013

[5] M. Atilhan, S. Aparicio, F. Karadas, K. R. Hall, and R. Alcalde, "Isothermal P $\rho \mathrm{T}$ measurements on Qatar's North Field type synthetic natural gas mixtures using a vibrating-tube densimeter," J. Chem. Thermodyn., vol. 53, pp. 1-8, 2012. https://doi.org/10.1016/j.jct.2012.04.008

[6] K. E. Starling and J. L. Savidge, Compressibility factors of natural gas and other related hydrocarbon gases. AGA, American Gas Association, 1994.

[7] F. E. Londono, R. A. Archer, and T. A. Blasingame, "Simplified Correlations for Hydrocarbon Gas Viscosity and Gas Density - Validation and Correlation of Behavior Using a Large-Scale Database." Society of Petroleum Engineers.

[8] D. L. Gysling, "An aeroelastic model of Coriolis mass and density meters operating on aerated mixtures," Flow Meas. Instrum., vol. 18, no. 2, pp. 69-77, 2007.

https://doi.org/10.1016/j.flowmeasinst.2006.12.006

[9] P. M. Dranchuk and J. H. Abou-Kassem, "Calculation of Z Factors for Natural Gases Using Equations of State.," J. Can. Pet. Technol., vol. 14, no. 3, pp. 34-36, 1975.

https://doi.org/10.2118/75-03-03

[10] S. Ketabchi, H. Ghanadzadeh, A. Ghanadzadeh, S. Fallahi, and M. Ganji, "Estimation of VLE of binary systems (tert-butanol+ 2-ethyl-1-hexanol) and (n-butanol+2-ethyl-1-hexanol) using GMDH-type neural network," J. Chem. Thermodyn., vol. 42, no. 11, pp. 1352-1355, 2010. https://doi.org/10.1016/j.jct.2010.05.018

[11] A. R. Moghadassi, F. Parvizian, S. M. Hosseini, and A. R. Fazlali, "A new approach for estimation of PVT properties of pure gases based on artificial neural network model," Brazilian J. Chem. Eng., vol. 26, no. 1, pp. 199-206, 2009. https://doi.org/10.1590/S0104-66322009000100019

[12] M. Kamyab, J. H. B. Sampaio, F. Qanbari, and A. W. Eustes, "Using artificial neural networks to estimate the z-factor for natural hydrocarbon gases,” J. Pet. Sci. Eng., vol. 73, no. 3, pp. 248-257, 2010. https://doi.org/10.1016/j.petrol.2010.07.006

[13] P. J. McElroy, R. Battino, and M. K. Dowd, "Compression-factor measurements on methane, carbon dioxide, and (methane+ carbon dioxide) using a weighing method," J. Chem. Thermodyn., vol. 21, no. 12 , pp. $1287-1300,1989$. https://doi.org/10.1016/0021-9614(89)90117-1

[14] M. Farzaneh-Gord, H. Reza Rahbari, and M. Deymi-Dashtebayaz, "Effets des compositions de gaz naturel sur le processus de remplissage rapide de GNC pour un système de stockage tampon," Oil Gas Sci. Technol., vol. 69, no. 2, pp. 319-330, 2014 https://doi.org/10.2516/ogst/2012010 